\title{
Penerapan desain pada permainan anak berkebutuhan khusus
}

\author{
Nadilla Ramadhita* \\ Program Studi Desain Produk, Institut Teknologi Bandung, Indonesia
}

\begin{abstract}
In daily life at least there is one product that we use to support our activities, ranging from clothing, cutlery, transportation, toiletries, games, and so forth. So also children who have limitations or special needs. In everyday life they also need a game that is able to stimulate their brain and motor. Design as a science that can meet the needs of these children has a very important role in this regard. As the times progress, children's games have designs that can meet the needs of their users.
\end{abstract}

Key words: product, diffable, game, motoric, design

\begin{abstract}
Abstrak
Dalam kehidupan sehari-hari setidaknya satu produk yang kita gunakan untuk menunjang aktivitas kita, mulai dari pakaian, alat makan, alat transportasi, alat mandi, permainan, dan sebagainya. Begitu juga dengan anak-anak yang memiliki keterbatasan atau berkebutuhan khusus. Dalam kesehariannya mereka juga membutuhkan permainan yang mampu menstimulasi otak serta motorik mereka. Desain sebagai suatu keilmuan yang dapat memenuhi kebutuhan anak-anak tersebut sangat berperan penting dalam hal ini. Seiring perkembangan zaman, permainan-permainan anak memilliki desain yang mampu memenuhi kebutuhan penggunanya.
\end{abstract}

Kata kunci: produk, berkebutuhan khusus, permainan, motorik, desain

\section{Pendahuluan}

Anak berkebutuhan khusus adalah anak yang memiliki perbedaan dalam keadaan dimensi penting dari fungsi kemanusiaannya. Mereka adalah secara fisik, psikologis, kognitif, atau sosial terhambat dalam mencapai tujuan/kebutuhan dan potensinya secara maksimal, sehingga memerlukan penanganan yang terlatih dari tenaga professional (Suran \& Rizzo, 1979). Anak-anak berkebutuhan khusus tidak selalu menunjukkan keterbatasan mereka. Namun aktivitas yang dilakukan terhambat akibat ketidakmampuan mental, fisik serta emosional.

Anak-anak berkebutuhan khusus memerlukan kasih sayang dan perhatian lebih dari lingkungan rumah maupun lingkungan sekolah mereka. Hal tersebut diperlukan sebagai suatu cara untuk menstimulasi otak, fisik, mental dan juga emosional mereka. Perhatian tersebut juga diperlukan karena anak-anak berkebutuhan khusus memiliki karakteristik yang berbeda dengan anak-anak pada umumnya. Anak berkebutuhan khusus berbeda dengan anak-anak pada umumnya. Mereka berproses dan tumbuh tidak dengan modal fisik yang wajar. Karenanya mereka cenderung defensive (menghindar), rendah diri, atau mungkin agresif, serta memiliki semangat belajar yang rendah (Purwanti, 2012).

Pada masalah ini, dunia desain dapat berperan penting dalam mendukung proses pembelajaran maupun permainan anak-anak berkebutuhan khusus. Sebagaimana yang telah dijelaskan bahwa anak-anak berkebutuhan khusus memiliki karakteristik yang berbeda dengan anak-anak pada umumnya. Dan hal tersebut berlaku juga pada apa yang mereka gunakan sehari-hari. Salah satunya ialah permainan yang dapat digunakan untuk membantu anak berkebutuhan khusus dalam menstimulasi otak serta gerak motorik mereka.

\footnotetext{
* Koresponden penulis e-mail: nadilla4@yahoo.com
} 
Tulisan ini bertujuan untuk menjadi bahan acuan bagi para desainer maupun orangtua dan guru dalam menerapkan desain serta memilih jenis permainan yang baik untuk anak-anak berkebutuhan khusus. Yang nantinya dapat bermanfaat bagi para penulispenulis lainnya untuk membuat sebuah jurnal ilmiah dengan tema desain bagi anak berkebutuhan khusus. Sehingga para desainer-desainer dapat memanfaatkan tulisan ini sebagai bahan pertimbangan dalam membuat sebuah desain mainan untuk anak berkebutuhan khusus.

\section{Bahan dan metode}

Metode yang digunakan adalah deskriptif analitis yaitu mendeskripsikan pokok penerapan desain dalam permainan anak berkebutuhan khusus, dan apa saja yang harus diketahui mengenai anak berkebutuhan khusus sebelum membuat sebuah desain mainan yang berguna untuk menstimulasi otak serta motorik mereka. Data diambil melalui riset dari berbagai sumber di internet seperti jurnal pribadi, karya tulis, maupun blog atau website.

\section{Hasil dan pembahasan}

Desain tidak pernah luput dari kehidupan manusia. Kegiatan sehari-hari memerlukan desain dalam penggunaannya. Sama hal nya dengan suatu produk yang digunakan manusia, produk tersebut memerlukan desain untuk memenuhi kebutuhan manusia dalam menjalankan aktivitas.

Bruce Archer, seorang ahli metodologi desain, mengatakan bahwa desain adalah salah satu bentuk kebutuhan badani dan rohani manusia yang dijabarkan melalui berbagai bidang pengalaman, keahlian, dan pengetahuannya yang mencerminkan perhatian pada apresiasi dan adaptasi terhadap sekelilingnya, terutama yang berhubungan dengan bentuk, komposisi, arti, nilai, dan berbagai tujuan benda buatan manusia (Sachari, 2005). Sama halnya dengan orang normal, anak-anak berkebutuhan khusus juga memerlukan desain untuk memenuhi kebutuhan hidupnya. Salah satunya yaitu alat bermain yang dapat menstimulasi otak, fisik, mental, serta motorik mereka. Permainan anak berkebutuhan khusus memerlukan desain yang khusus pula dalam pembuatannya. Karena permainan-permainan tersebut harus memiliki fungsi yang dapat mendukung aktivitas sehari-hari. Anak berkebutuhan khusus memiliki perbedaan-perbedaannya sendiri. Ada bermacam-macam jenis anak dengan kebutuhan khusus (Delphie, 2006; Hallahan \& Kauffman, 2006), yaitu (1) Tunanetra. Yang dimaksud dengan tunanetra adalah anak yang mengalami gangguan daya penglihatan berupa kebutaan menyeluruh atau sebagian; (2) Tunarungu. Tunarungu merupakan anak yang mengalami gangguan pendengaran sebagian atau menyeluruh sehingga tidak atau kurang mampu berkomunikasi secara verbal; (3) Tunadaksa, yaitu anak yang mengalami kelainan atau cacat yang menetap pada alat gerak (tulang, sendi, otot); (4) Berbakat/memiliki kemampuan luar biasa. Anak berbakat merupakan anak yang memiliki potensi kecerdasan (inteligensi), kreativitas, dan tanggung jawab terhadap tugas di atas anak-anak seusianya (anak normal), sehingga untuk mewujudkan potensinya menjadi prestasi memerlukan pelayanan khusus; (5) Tunagrahita, yaitu anak yang secara nyata mengalami hambatan dan keterbelakangan perkembangan mental jauh di bawah rata-rata sedemikian rupa sehingga mengalami kesulitan dalam tugas-tugas akademik, komunikasi maupun sosial; (6) Lamban belajar. Yang dimaksud dengan lamban belajar adalah anak yang memiliki intelektual sedikit di bawah normal tetapi belum termasuk tunagrahita. Mengalami keterlambatan berpikir, merespon rangsangan, adaptasi sosial; (7) Kesulitan belajar spesifik, yaitu anak yang secara nyata mengalami kesulitan dalam tugas akademik khusus, terutama membaca, menulis, dan berhitung. Disebabkan faktor disfungsi neurologis bukan inteligensi. Anak berkesulitan belajar spesifik dapat berupa kesulitan belajar membaca (disleksia), kesulitan belajar menulis (disgrafia), atau kesulitan belajar berhitung (diskalkulia); (8) Mengalami gangguan komunikasi, yaitu anak yang mengalami kelainan suara, artikulasi (pengucapan), atau kelancaran bicara, yang mengakibatkan terjadi penyimpangan bentuk Bahasa, isi Bahasa, atau fungsi Bahasa; (9) Tunalaras. Tunalaras merupakan anak yang mengalami kesulitan dalam penyesuaian diri dan bertingkah laku tidak sesuai dengan norma-norma yang berlaku dalam lingkungan kelompok usia maupun masyarakat pada umumnya, sehingga merugikan dirinya maupun orang lain; (10) ADH/GPPH (Gangguan Pemusatan Perhatian dan Hiperaktivitas), yaitu sebuah gangguan yang muncul pada anak dan dapat berlanjut hingga dewasa dengan gejala meliputi gangguan pemusatan perhatian dan kesulitan untuk fokus, mengontrol perilaku, dan hiperaktif (overaktif). Gejala tersebut harus tampak sebelum usia 7 tahun dan bertahan minimal selama 6 bulan; (11) Autisme, yaitu gangguan perkembangan yang kompleks. Meliputi gangguan komunikasi, interaksi sosial, dan aktivitas imaginatif, yang mulai tampak sebelum anak berusia 
tiga tahun, bahkan anak yang termasuk autism infantile gejalanya sudah muncul sejak lahir.

Pelatihan untuk orang-orang yang bersinggungan dengan anak berkebutuhan khusus -misalnya orang tuanya- sangat diperlukan agar anak berkebutuhan khusus tersebut dapat ditangani dengan benar sesuai dengan kebutuhannya (Roihah, 2015). Selain itu, diperlukan pula desain alat permainan yang khusus dirancang untuk membantu anak berkebutuhan khusus beraktivitas.

Berdasarkan pembagian jenis anak berkebutuhan di atas dapat dikatakan bahwa jenis permainan yang dapat mendukung aktivitas anak juga dibedakan menurut kebutuhannya. Permainan-permainan tersebut diharapkan dapat meningkatkan kemampuan imajinasi, komunikasi, gerak, serta bersosialisasi secara maksimal dengan lingkungan sekitar. Adapun penerapan desain yang dapat dilakukan hendaknya mengacu pada apa yang ingin dituju dan jenis anak dengan kebutuhan khusus apa yang ingin dicapai.

Desain yang dapat diterapkan dalam permainan anak hendaknya memperhatikan beberapa aspek sebagai berikut: (1) Dapat melatih keseimbangan; (2) Bahan yang digunakan aman; (3) Visual yang menarik; (4) Mudah digunakan dan cepat dipahami; (5) Bentuk yang menarik; (6) Dapat melatih imajinasi dan daya pikir; dan (7) Dapat meningkatkan fokus dan konsentrasi. Ada banyak contoh alat permainan yang dapat digunakan untuk anak berkebutuhan khusus. Beberapa di antaranya akan dibahas di bawah ini, yaitu: Fidget Dice, Spiky Sensory Ring, Peg Board Set, Awesome Flake 300 Disc Building Set, dan Gonge Riverstones.

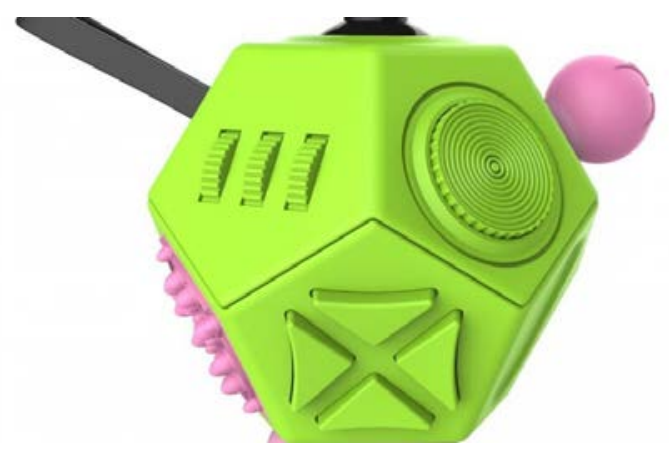

Gambar 1. Fidget Dice

(Sumber : https://www.fokusfied.com/fidget-toys-help-adhd-add/)

Gambar 1 memperlihatkan suatu alat permainan yang disebut Fidget Dice yang dirancang khusus untuk permainan jari. Alat permainan ini diklaim dapat meningkatkan fokus, daya pikir, serta melatih motorik untuk anak berkebutuhan khusus, utamanya anak dengan ADHD (Attention Deficit Hyperactivity
Disorder), ADD (Attention Deficit Disorder), OCD (obsessive-compulsive disorder), dan penderita autis. Permainan tersebut juga dibuat dari bahan yang aman digunakan karena menggunakan plastik berkualitas.

Gambar 2 memperlihatkan suatu alat permainan yang disebut Spiky Sensory Ring yang dapat digunakan oleh semua umur khususnya anak berkebutuhan khusus. Permainan ini dapat membantu meningkatkan ketenangan, mengurangi stress atau kecemasan dan meningktakan fokus. Mainan ini juga dirancang khusus untuk meningkatkan daya sensorik anak sebagai cara untuk menstimulasi otak anak.

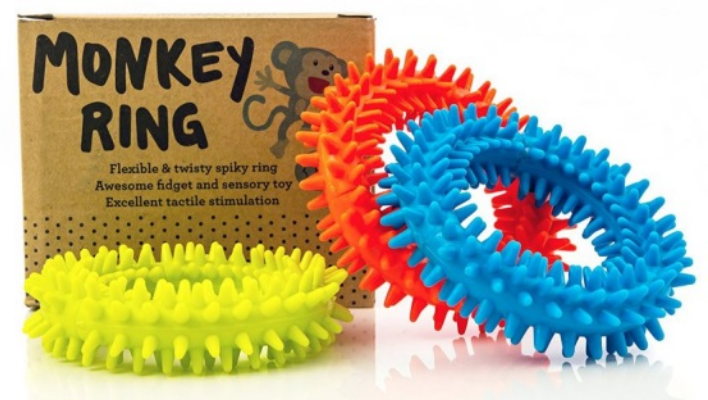

Gambar 2. Spiky Sensory Ring

(Sumber : https://www.fokusfied.com/fidget-toys-help-adhd-add/)

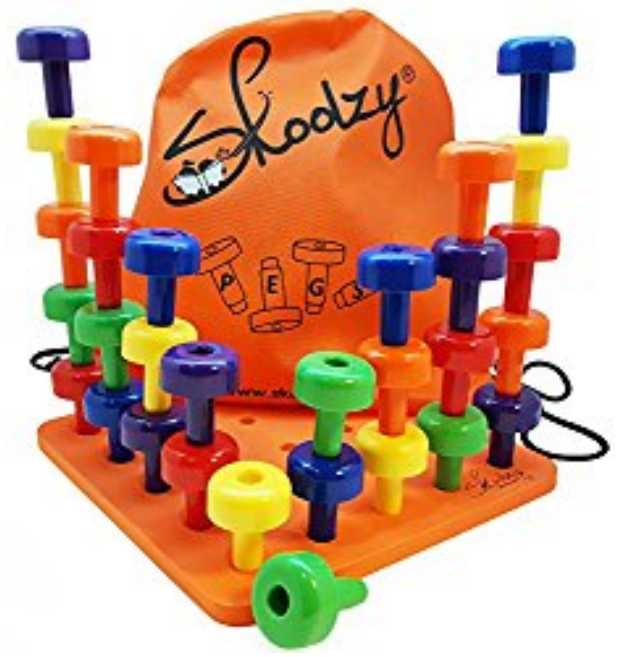

Gambar 3. Peg Board Set

(Sumber : https://crayonboxchronicles.com/2015/11/16/best-toyssensory-seekers/)

Alat permainan lainnya adalah Peg Board Set. Alat ini dapat mengembangkan kekuatan fisik anak serta melatih kemampuan motorik (Gambar 3). Warnawarna yang diterapkan pada desain mainan ini juga dapat melatih kemampuan visual anak berkebutuhan khusus. Melatih keterampilan serta melatih fokus dan konsentrasi.

Berbeda halnya dengan alat permainan yang disebut Awesome Flake 300 Disc Building Set ini. 
Alat permainan ini dirancang seperti puzzle yang dapat dibongkar-pasang sehingga dapat menstimulasi kinerja otak dan dapat dijadikan terapi bagi anak berkebutuhan khusus (Gambar 4). Permainan ini dapat meningkatkan fokus, kesabaran, pengembangan sensorik, keterampilan spasial dan penguatan ketangkasan pergelangan tangan. Desain yang diterapkan pada permainan ini ditujukan untuk anakanak dengan menerapkan warna-warna terang dan bentuknya yang mudah dipahami.

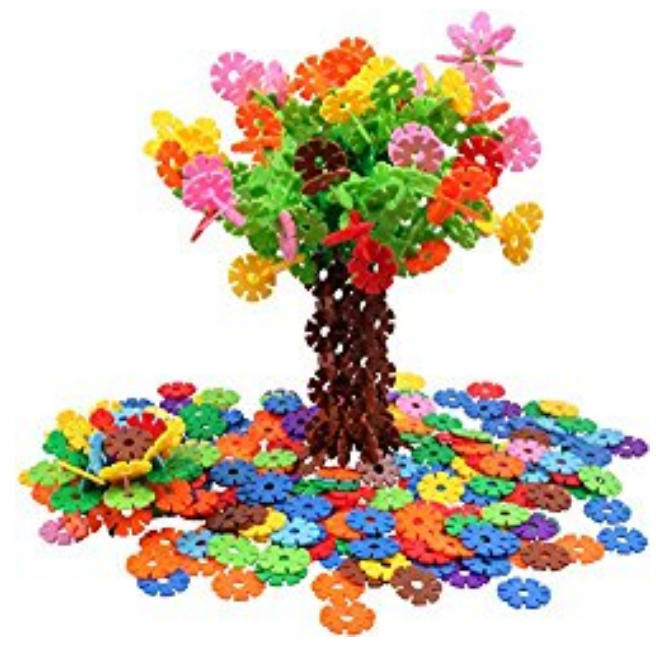

Gambar 4. Awesome Flakes 300 Disc Building Set (Sumber : https://crayonboxchronicles.com/2015/11/16/best-toyssensory-seekers/)

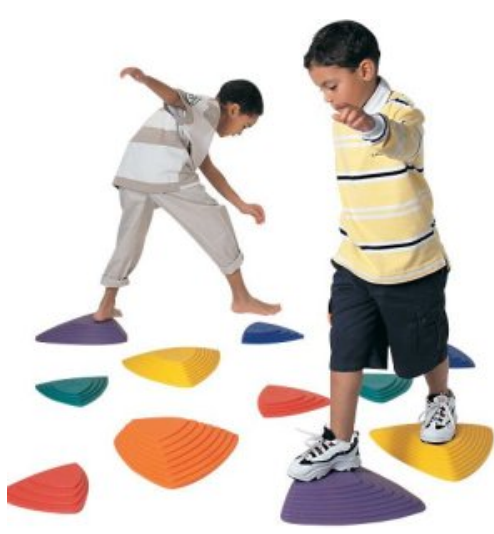

Gambar 5. Gonge Riverstones

(Sumber : https://crayonboxchronicles.com/2015/11/16/best-toyssensory-seekers/)

Alat permainan untuk anak berkebutuhan khusus lainnya adalah Gonge Riverstones. Alat permainan ini dapat meningkatkan koordinasi dan keseimbangan bagi anak berkebutuhan khusus, serta dapat meningkatkan konsentrasi dan fokus seperti tampak pada Gambar 6. Desain yang digunakan pada permainan tersebut dapat menstimulasi kemampuan sensorik anak serta warna yang digunakan bervariatif sehingga dapat mengembangkan kemampuan visual anak berkebutuhan khusus.

\section{Kesimpulan}

Berdasarkan pemaparan desain yang diterapkan pada permainan anak berkebutuhan khusus tersebut, para desainer sangat memperhatikan target yang ingin dicapai. Mulai dari umur, jenis permainan, dan kemampuan apa yang ingin ditingkatkan oleh pengguna. Seiring dengan perkembangan zaman sekarang ini, jenis-jenis permainan untuk anak berkebutuhan khusus juga semakin beragam. Dengan kualitas yang beragam pula.

Para desainer diharapkan selalu memperhatikan kualitas produk yang ingin dipasarkan. Karena pengguna yang memakai produk tersebut adalah anak-anak dengan karakteristik yang berbeda dengan anak normal lainnya. Maka dari itu perlu adanya perhatian khusus dari para desainer dalam pembuatan mainan anak berkebutuhan khusus. Orangtua serta guru juga ikut andil dalam pemilihan permainan anak berkebutuhan khusus yang sesuai dengan kebutuhan anak tersebut. Agar nantinya kemampuan anak dapat berkembang mulai dari kemampuan motorik, komunikasi, sensorik, maupun mental anak dengan kebutuhan khusus tersebut.

\section{Daftar pustaka}

Delphie, B. (2006). Pendidikan Anak Berkebutuhan Khusus. Jakarta: Rineka Cipta.

Hallahan, D. P., \& Kauffman, J. M. (2006). Exceptional Learners: Introduction to Special Education 10th ed. Boston: Allyn \& Beacon.

Purwanti, I. (2012). Studi kasus tentang pemahaman orang tua yang memiliki anak berkebutuhan khusus di SDN Kembangan Kecamatan Kebomas Kabupaten Gresik. Universitas Islam Negeri Maulana Malik Ibrahim, Malang. Retrieved from http://etheses.uin-malang.ac.id/2258/

Roihah, A. I. H. (2015). Efektifitas pelatihan incredible mom terhadap peningkatan sikap penerimaan orangtua dengan kondisi anak berkebutuhan khusus. Universitas Islam Negeri Maulana Malik Ibrahim, Malang. Retrieved from http://etheses.uin-malang.ac.id/1484/

Sachari, A. (2005). Pengantar Metodologi Penelitian Budaya Rupa: Desain, Arsitektur, Senirupa, dan Kriya. Jakarta: Penerbit Erlangga.

Suran, B. G., \& Rizzo, J. V. (1979). Special children: An integrative approach. Illinois: Scott Foresman. https://doi.org/10.1002/1520-6807 